\title{
CONTRIBUIÇÕES DA TEORIA SÓCIO-HISTÓRICA PARA O ENSINO E A APRENDIZAGEM EM FÍSICA DE ESTUDANTES DA PRIMEIRA SÉRIE DO ENSINO MÉDIO
}

\author{
Social-historical contributions' theory for learning and teaching physics for \\ students at first year of high school
}

\author{
Odifax Quaresma Pureza \\ Luiz Marconi Fortes Magalhães ${ }^{2}$
}

\section{RESUMO}

O presente estudo buscou compreender a forma pela qual estudantes de série inicial do ensino médio constroem o conceito de energia mecânica e suas formas, na ótica da Teoria Sócio-Histórica, desenvolvida pelo russo Lev Semenovich Vygotsky, colaboradores e seguidores. Valemo-nos, para esta análise, da abordagem metodológica denominada de análise microgenética, mas precisamente das categorias propostas por Mortimer e Scott (2002). Foi analisado um episódio de ensino decorrente da interação entre o professor e um grupo de três estudantes, através do qual procurou-se evidenciar as intenções do professor, o conteúdo do discurso, a abordagem comunicativa, os padrões de interação e as formas de intervenções do professor.

Palavras-chave: Ensino de Física. Energia Mecânica. Teoria Sócio-Histórica. Análise Microgenética.

\section{ABSTRACT}

The Present Study tried to understand the way students from beginners level of the middle teaching build the concept of mechanic energy and its forms, in the optic of the social-historic theory, developed by the Russian Lev Semenovich Vygotsky, contributors and followers. We are based, to this analysis, on the methodological approach called microgenetic analysis, with more accuracy, on the categories proposed by Mortimer and Scott (2002). It was analyzed an episode of teaching due to the interaction between the teacher and a group of three students, where we tried to make evident the intentions of the teacher, the content of the speech, the communicative approach, the interaction patterns and the teacher's interventions' ways.

Key-words: Physics Teaching. Mechanic Energy. Social-Historic Theory. Microgenetic Analysis.

\section{O CAMINHO E A PROPOSTA DA INVESTIGAÇÃO}

A ação docente em salas de aula no ensino de Física, na Educação Básica, proporcionou-nos a oportunidade de vivenciar dificuldades comumente encontradas por professores e estudantes relacionadas à construção do conhecimento ligadas a esta disciplina escolar. Este cenário nos levou a realizar um estudo no sentido de compreender a forma pela qual estudantes, de série inicial do ensino médio, constroem o conceito de energia mecânica e suas formas. $\mathrm{Na}$ análise dos processos de ensino e aprendizagem, buscou-se identificar, nas explicações construídas nas interações em sala de aula, os elementos que pudessem indicar ou evidenciar a forma de os estudantes construírem o conceito de energia mecânica e suas formas, na ótica da Teoria Sócio-Histórica, desenvolvida pelo russo Lev Semenovich Vygotsky, colaboradores e seguidores.

Para realizar a análise do estudo, recorremos à abordagem metodológica denominada de análise microgenética, mas precisamente aquelas das categorias propostas por Mortimer e Scott (2002). Estes autores mostram que estas categorias buscam

\footnotetext{
${ }^{1}$ Mestre em Educação em Ciências e Matemáticas - NPADC/UFPA, Professor do Núcleo pedagógico Integrado NPI/UFPA.

${ }^{2}$ Ph.D. em Ciências do Meio Ambiente-UQAM/Canadá, Diretor do Núcleo pedagógico Integrado - NPI/UFPA.
} 
evidenciar as intenções do professor, o conteúdo do discurso, a abordagem comunicativa, os padrões de interação e as formas de intervenções do professor.

O estudo foi desenvolvido em uma sala de aula de Física, com uma turma de primeira série do ensino médio de uma escola pública de Belém, composta por 34 estudantes, com idade variando de 14 a 16 anos, no ano letivo de 2003, sendo o professor da disciplina escolar Física o próprio pesquisador e o primeiro autor do referido estudo e o outro o respectivo orientador.

Para selecionar os episódios observados durante a coleta de dados, para serem analisados pela proposta deste estudo, tomou-se, como critério metodológico, a forma como cada grupo construiu, na interação com o professor, a resposta para a seguinte questão: em que tipo de energia, a energia mecânica associada à esfera no ponto A do plano inclinado, se transformaria ao chegar no ponto $B$ do mesmo.

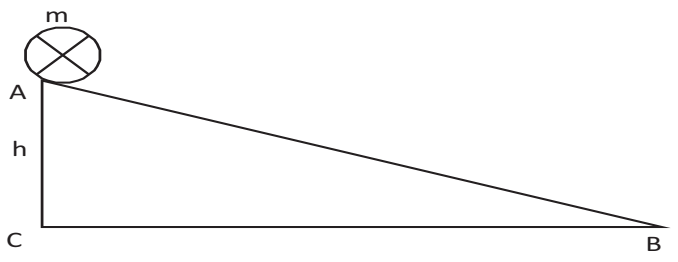

Figura 1 - Plano inclinado

Convém observar que a energia mecânica forma de energia associada à posição de corpos interagentes, denominada energia potencial, ou devido aos seus movimentos, denominada energia cinética - é uma das formas em que a energia pode se apresentar. A energia, segundo o seu princípio de conservação, não pode ser criada nem destruída. Pode apenas ser transformada de uma forma para outra, com sua quantidade total permanecendo constante. No caso particular em que uma esfera desce um plano inclinado, a energia mecânica associada à esfera no ponto A do plano, enquanto se encontra em repouso em relação ao plano, será do tipo potencial gravitacional. A partir do momento em que for abandonada e entrar em movimento, parte desta energia será transformada em outra modalidade de energia mecânica, do tipo cinética, além de outras modalidades de energia, como a sonora e a calorífica, em função, por exemplo, da resistência do ar e do atrito entre a esfera e o plano. Ao atingir o ponto B do plano, considerado como nível de referência, a forma de energia mecânica será do tipo cinética, ou seja, a energia potencial gravitacional associada à esfera no ponto $\mathrm{A}$ do plano se transforma em energia cinética mais a energia dissipada na descida ao atingir o ponto B do mesmo. Neste estudo, no entanto, iremos considerar desprezíveis o atrito e a resistência do ar, bem como o fato de que a esfera desce o plano rolando sem deslizar, ou seja, consideraremos apenas a modalidade mecânica da energia associada à esfera.

As aulas foram gravadas em vídeo e posteriormente transcritas. Diante do relato apresentado, passaremos a mostrar as analises das interações ocorridas entre o professor e um grupo composto por três estudantes aqui denominados de E13, E28 e E31. O episódio decorrente desta interação foi divido em quatro segmentos a seguir, de acordo com os passos dados pelos estudantes rumo à explicação que estava sendo construída. Os turnos das falas referentes a cada segmento foram utilizados para ilustrar o estudo e são mostrados no final de cada segmento.

\section{O PROCESSO E AS ANÁLISES DA INVESTIGAÇÃO}

No segmento 1 - o professor atua no sentido de que os estudantes desfaçam o equívoco entre os termos potência e energia, o que parece ocorrer, pelo menos para o estudante E31, no turno 13. Como o estudante E28 não compartilha destes significados, o professor, no segmento 2, oferece para o grupo uma definição de potência.

No segmento 3, o professor interage para que os estudantes relacionem energia potencial gravitacional e altura, no segmento 4, esta interação ocorre na busca de relacionar energia cinética com velocidade e de que esta ocorre, na situação em estudo, a partir da mudança de altura ocorrida com aquela. 


\section{Segmento 1: Potência é energia?}

Neste segmento que vai do turno 03 ao turno 14, o professor buscava fazer com que os estudantes explicassem, em que forma de energia, a energia potencial gravitacional associada à esfera no ponto $\mathrm{A}$, se transformaria ao descer o plano inclinado. Mas, no momento da interação, o grupo confunde potência com energia.

Em função da afirmação elucidada pelo estudante E31 no turno 03 de que a energia potencial gravitacional se transformaria em potência, inadequada do ponto de vista do conceito escolar de energia, o professor, no turno 04, intervém no sentido de proporcionar um outro entendimento para o grupo, ao questionar: a energia potencial gravitacional (...) vai se transformar em potência?

$\mathrm{Na}$ tentativa de responder ao questionamento do professor, o estudante E31, no turno 07 , demonstra uma certa dificuldade para articular o pensamento. Nesse momento, parece-nos que ele, assim como os demais elementos do grupo, começam a criar consciência de que há algum equívoco, de que precisam reelaborar o pensamento no sentido de estabelecer novas coordenações mentais, o que nos deixa entender ser consistente com a forma como o professor interagiu com o grupo.

Como reflexo da compreensão de que precisavam refazer seus conceitos, os componentes do grupo voltaram a fazer novas conjecturas, como podemos perceber, através das interações estudante/estudante ocorridas nos turnos 09, 10 e 11, respectivamente: (...) ela começa a descer; A energia começa a ser transformada e É, a energia vai ser transformada (...).

O professor, então, no turno 12 repete o enunciado dos estudantes, a energia vai ser transformada, o que evidencia uma avaliação, sinalizando para os estudantes que até àquele ponto a explicação está adequada, ao mesmo tempo em que ressalta elementos essenciais para a elaboração da resposta da situação em questão.

Entretanto, como isso representava apenas uma parte da explicação que os alunos deveriam fornecer, o professor inclui em sua avaliação, dois questionamentos, de potencial gravitacional em potência? e potência é energia? Esta situação ocorreu para podermos relacionar o que os estudantes já sabiam com o que ainda precisavam saber, trabalhando dessa forma dentro de uma ZDP mais ou menos comum ao grupo.

O estudante E31, no turno 13, responde "não" e o professor marca/reforça/avalia no turno 14. Aqui, o estudante E31 demonstra compreender que potência não é energia e, como os demais elementos do grupo não manifestam uma opinião em contrário, fica parecendo que a fala do estudante E31 corresponde à fala do grupo. O que indicaria a compreensão de que o grupo havia internalizado o fato de que potência não é energia.

O conteúdo do discurso no qual se engajou o professor nesta sequência de interações com os estudantes varia de uma forma que pode ser caracterizada como interativa dialógica, quando, no turno 06, utiliza-se de um "porque", com o intuito de que o estudante possa explicar melhor sua afirmação anterior, para uma forma interativa de autoridade, na qual, nos turnos $12 \mathrm{e}$ 14 , atua de forma avaliativa.

Para tanto, desenvolve uma cadeia de interações do tipo $I-R-F-R \ldots$, fornece um feedback e solicita do grupo uma elaboração adicional em relação as suas afirmações, bem como, do tipo $I-R-A$, ao se posicionar de forma avaliativa em relação às elaborações dos estudantes.

A ação do professor, nessa sequência, é observada com a intenção de elucidar e explorar as visões e entendimentos dos estudantes, de modo a levar os mesmos a concluírem que potência não é energia. Neste sentido, a intervenção do professor ocorre de forma a permitir que os estudantes procurem explicar melhor as suas ideias de que a energia vai se transformar em potência.

O conjunto de interações acima, além de caracterizar um discurso cujo conteúdo pode ser caracterizado como uma explicação dirigida pela teoria, sugere, ainda, que o compartilhamento dos significados no plano 
interpsicológicos parecem querer migrar para o plano intrapsicológico.

\section{Turnos de falas referentes ao segmento 1}

(03) E31. O que acontecerá com está energia a partir do momento em que a esfera começa a descer o plano inclinado (estudante lê a Questão 2)? Ficou potência.

(04) P. A energia potencial gravitacional, à medida que vai descer aqui (o professor aponta para o plano inclinado representado na ficha do estudante), à medida que a esfera vai descer, vai se transformar em potência?

(05) E31. Vai.

(06) P. Por quê?

(07) E31. Devido, é, parece que é, é, .... , ta perguntando, me esqueci agora, é uma variação de, $\ldots$, não sei o que.

(08) E31. Ininteligível.

(09) E31. Ela ainda está descendo, né? A partir que, ela começa a descer...

(10) E28. A energia começa a ser transformada....

(11) E31. É, a energia vai ser transformada, aí ela.....

(12) P. A energia vai ser transformada, de potencial gravitacional em potência?......, potência é energia?

(13) E31. Não.

(14) P. Não.

\section{Segmento 2: então, o que é potência?}

Neste segmento, que vai do turno 15 ao turno 25, enquanto o estudante E31 começa a rever os conceitos dos diferentes tipos de energia mecânica, no sentido de oferecer uma explicação para a situação em estudo, o estudante E28 demonstra não compartilhar os significados construídos nas interações anteriores, ao se posicionar nos turnos 17, 19 e 24.

Dessa forma, o professor retoma a questão discutida do episódio anterior, ao se manifestar nos turnos 18 e 21 (em que questiona: $O$ que é potência?), na perspectiva de desfazer a confusão existente entre potência e energia, tentando levar, dessa forma, o estudante E28 a definir o que é potência e por consequência compreender que potência não é energia.

Nas interações que vão do turno 17 até o turno 21, há uma oscilação entre a intenção do professor (definir o que é potência), o estudante E28 persistindo no questionamento se potência é energia e o estudante E31 dizendo que potência não é energia.

Em mais uma tentativa de que o próprio estudante E28 concluísse que potência não é energia, o professor no turno 22, faz um feedback da conclusão já feita pelo estudante E31 no turno 15, Vocês já falaram que tem três tipos de energia mecânica. Vocês já me falaram quais são os três, e refaz a pergunta: Potência é energia?. Dessa forma, ao fazer uma intervenção destacando a existência de três tipos de energia mecânica, sinaliza para os estudantes que potência não é energia.

Embora a intenção do professor não tenha sido atendida, a interação acima serviu para que o estudante E28 assumisse, no turno 24: Então não sei o que é potência (...). Diante do que, o professor, no turno 25 , oferece uma definição para potência, num posicionamento que reflete um discurso interativo de autoridade, e um padrão de interação do tipo $I-R-A$.

A definição fornecida pelo professor mostrou-se necessário, no momento, a fim de dar continuidade à intenção inicial de que os estudantes explicassem em que tipo de energia mecânica, a energia associada à esfera no ponto A se transformaria ao descer o plano inclinado, intenção esta encaminhada pelo professor ao questionar: (...) é essa a situação da questão de vocês aí?

Neste sentido, sua ação se dá, inicialmente, com a intenção de guiar os estudantes no trabalho com as ideias cientificas no sentido de buscar compartilhar significados em relação ao termo potência e, em seguida, no sentido de disponibilizar está ideia ao grupo.

A sua intervenção variou entre marcar significados para a construção da estória 
científica, e introduzir um termo novo (a definição de potência), de modo que os estudantes pudessem fazer a diferença entre energia e potência.

Neste episódio, as interações entre os estudantes e o professor não ocorreram de forma que permitissem aos mesmos construírem algum tipo de explicação, ou mesmo uma descrição dos fatos em discussão.

\section{Turnos de falas referentes ao segmento 2}

(15) E31. Cinética. Olha, energia cinética, potencial gravitacional e elástica, não é mecânica?

(16) P. É energia mecânica.

(17) E28. Potência é energia mecânica professor?

(18) P. O que é que é potência?

(19) E28. É energia mecânica?

(20) E31. Não. Não é.

(21) P. Não. O que é potência?

(os alunos falam ao mesmo tempo)

(22) P. Vocês já falaram que tem três tipos de energia mecânica. Vocês já me falaram quais são os três. Potência é energia?

(23) E31. Não.

(24) E28. Então eu não sei o que é potência, nem trabalho.

(25) P. A potência é, a, a, .... , a rapidez com que a energia é transformada, rapidez com que é transformada, é essa a situação da questão de vocês aí?

\section{Segmento 3: porque tem altura não pode ter energia cinética?}

Superado o impasse relativo à questão de que potência seria ou não energia, discutido nos segmentos anteriores (segmentos 1 e 2), a atenção do professor se volta para o seu objetivo inicial, que é buscar que os estudantes expliquem, em que forma de energia, a energia potencial gravitacional associada à esfera no ponto A se transforma ao descer o plano inclinado.

Como um passo inicial, a interação entre o professor e os estudantes ocorrida no segmento transcrito a seguir, que vai do turno 29 ao turno 40, deu-se no intuito de que os estudantes explicassem qual tipo de energia mecânica poderia ser associada à esfera enquanto se encontrava em repouso no ponto A. É neste sentido que se dá o questionamento do professor no turno (29), (...) nesta situação aqui (...) ela tem energia potencial gravitacional?

Como o grupo demonstra estar elaborando mentalmente, mas não externaliza uma resposta, o professor, no turno 31, reelabora seu questionamento, focalizando um outro tipo de energia, de modo que os estudantes pudessem decidir quanto ao tipo de energia mecânica que estaria ali associada, se potencial gravitacional ou a cinética.

O estudante E31, nessa interação, reconhece que não pode ser associada à esfera energia cinética, enquanto esta se encontra no ponto Ado plano inclinado, entretanto, associa sua explicação à característica essencial da energia potencial gravitacional, que é ter altura. O professor refaz a pergunta duas vezes, no turno 33 e no turno 35, na intenção de que o estudante E31 compreenda que a esfera no ponto A não tem energia cinética porque está em repouso e não porque tem altura. No entanto, por duas vezes, nos turnos 32 e 34, o estudante E31, insiste em responder que não tem energia cinética porque tem altura.

Como resultado das interações professor/estudante E31, o estudante E28 parecendo compreender que havia algum equívoco com relação às associações entre altura e energia cinética, elaborada pelo estudante E31, começa no turno 37 a elaborar uma nova relação para altura dentro da explicação que estava sendo solicitada pelo professor. No turno 38, o professor considera a resposta até então elaborada pelo estudante E28, de que a esfera no ponto A, tem uma certa altura do nível de referência e solicita uma elaboração adicional do estudante E28, no sentido de que ele relacione altura com energia potencial gravitacional, o que condiz com a sua intervenção do turno 38: Então, por isso ela tem que tipo de energia? Devido à altura ela tem que tipo de energia?.

Em função da resposta fornecida pelo 
estudante E28, no turno 39, de que a forma de energia associada à esfera é a potencial gravitacional, a intervenção do professor, no turno 40 , se deu no sentido de confirmar a ideia contida na resposta do estudante, ao mesmo tempo em que acrescenta que a energia potencial gravitacional é um tipo de energia mecânica. Com isso, o professor chama a atenção dos estudantes de que existem outros tipos de energia mecânica, além da potencial gravitacional, o que poderia contribuir para a conclusão, por parte dos estudantes, da forma de energia mecânica, em que a energia potencial gravitacional seria transformada enquanto a esfera desce o plano inclinado.

A abordagem comunicativa foi do tipo interativa de autoridade, uma vez que a atuação do professor ocorreu no sentido de conduzir os estudantes rumo a uma explicação aceita do ponto de vista do conhecimento escolar, caracterizando um padrão de interação do tipo $I$ $-R-A$.

Atuando com a intenção de guiar os estudantes na aplicação das ideias científicas, o professor procura fazer suas intervenções no sentido de checar o entendimento dos estudantes no que diz respeito à forma de energia mecânica associada à esfera no ponto $\mathrm{A}$, o que leva os mesmos a oferecerem uma explicação que pode ser caracteriza como sendo dirigida pela teoria.

\section{Turnos de falas referentes ao segmento 3 .}

(29) P. Ta. Então vamos, ,.. , nesta situação aqui (aponta a situação na qual a esfera se encontra no ponto A do modelo, presente na questão 1), ela tem energia potencial gravitacional?

(30) E31. hum...

(31) P. Ela tem aqui, na questão, ela pode apresentar energia cinética na questão 1 ?

(32) E31. Não. Ela tem altura.

(33) P. Não? Por que ela não tem energia cinética?

(34) E31. Ela tem altura.

(35) P. Ela não tem energia cinética por que ela tem altura?

(36) E31.É....
(37) E28. Não, ela ta, ..., ela tem uma certa altura do nível de referência.

(38) P. Então, por isso ela tem que tipo de energia? Devido à altura ela tem que tipo de energia?

(39) E28. Potencial gravitacional.

(40) P. Potencial gravitacional, que é um tipo de energia mecânica.

Segmento 4: o que vai acontecer com a energia potencial gravitacional?

Internalizado o fato de que a energia mecânica associada à esfera no ponto A é a energia potencial gravitacional, o professor retoma o seu objetivo inicial de buscar que os estudantes expliquem, em que forma de energia, a energia potencial gravitacional associada à esfera no ponto A se transforma ao descer o plano inclinado.

Dando prosseguimento à busca da construção, pelos estudantes, da referida explicação, o professor conduz as discussões, como pode ser observado através das interações ocorridas nos turnos abaixo (42 a 56), de forma que a abordagem comunicativa decorrente destas interações pode ser caracterizada como sendo do tipo interativa de autoridade, com um padrão de interação condizente com a forma $I-$ $R-A$.

Neste sentido, o professor atua com a intenção de guiar os estudantes na aplicação das ideias cientificas, na busca de trabalhar os significados no desenvolvimento da explicação que os mesmos devem fornecer. As suas intervençôes ocorrem no sentido de checar o entendimento dos estudantes acerca do tema tratado.

No turno 55, o professor parafraseia etapas anteriores na busca de focalizar as ideias discutidas até então e de confirmar os aspectos essenciais necessários para a elaboração da explicação a ser fornecida pelos estudantes, explicação esta que pode ser caracterizada como dirigida pela teoria, pois os estudantes relacionam nesta explicação a presença da energia cinética com velocidade ou, sua ausência, com repouso.

Dessa forma, a ação do professor parece ter contribuído para que os estudantes chegassem à 
conclusão de que a energia potencial gravitacional se transforma em energia cinética na situação proposta.

\section{Turnos de falas referentes ao segmento 4}

(42) P. Mas, ela pode ter energia cinética nessa situação aí (aponta para a Questão 1)?

(43) E31. Pode.

(44) E28. Pode.

(45) P. Na situação da questão 1 ?

(46) E31. Não.

(47) E28. Ah!,..., Não.

(48) P. Por que ela não pode, nessa situação, ter energia cinética?

(49) E31. Porque, energia cinética, ela não se relaciona com a altura.

(50) P. Relaciona com o que?

(51)E31. Com velocidade.

(52) P. Com velocidade. Ela tem velocidade?

(53) E28. Não.

(54) E31. Ta em repouso.

(55) P. Não. Por conta dela estar em repouso, ela não tem energia cinética, ela só tem energia potencial gravitacional. À medida que ela for abandonada, que é a situação da questão 2 , que é que vai acontecer com a energia potencial gravitacional?

(56) E31. Vai se transformar em energia cinética.

\section{CONSIDERAÇÕES FINAIS}

A sequência de ensino e de aprendizagem apresentada neste estudo emergiu como consequência de uma situação problema planejada com o intuito de que os estudantes, interagindo entre si e com o professor, construíssem uma explicação para a seguinte questão: em que tipo de energia, a energia mecânica associada a uma esfera, no ponto A de um plano inclinado, se transformaria, ao chegar no ponto B do mesmo?

A análise desta sequência mostrou que as intervenções do professor, no grupo selecionado para este estudo, contribuíram de forma decisiva para que os estudantes chegassem à explicação desejada do ponto de vista do conhecimento escolar, tendo a explicação dos estudantes se iniciado com os mesmos confundindo os conceitos de energia potencial gravitacional e potência. $\mathrm{O}$ professor atuou, primeiro, no sentido de desfazer este equivoco e, em seguida, contribuir para que os estudantes construíssem a sua explicação para situação em questão.

Para atingir este objetivo, o professor utilizou, em alguns momentos, uma abordagem comunicativa interativa dialógica, momento em que aceitava, pelo menos temporariamente, as argumentações dos estudantes e, em outros, uma abordagem comunicativa interativa de autoridade, na qual o desenrolar das ações desenvolvidas contou sempre com a participação dos estudantes e com o professor atuando no sentido de conduzir os estudantes em direção à explicação desejada.

Os padrões de interações gerados foram, em alguns momentos, do tipo $I-R-A$, nos quais, a partir de uma iniciação por parte do professor, ocorria uma resposta por parte dos estudantes e, em seguida, a avaliação do professor para esta resposta, em outro momento, do tipo $I-R-F-R$.... O professor fornecia um feedback com o intuito de permitir que os estudantes pudessem elaborar um pouco mais as suas falas.

Deste modo, as intenções do professor, durante as suas intervenções, estiveram voltadas ora no sentido de explorar a visão $e$ entendimento dos estudantes acerca de ideias ou fenômenos específicos, ora no sentido de introduzir ou desenvolver a história científica, ao disponibilizar as ideias científicas no plano social da sala de aula, ou ainda, no sentido de guiar e manter a narrativa dos estudantes rumo à construção desta história.

As formas das intervenções pedagógicas do professor variaram entre dar forma aos significados atribuídos pelos estudantes ou checar o seu entendimento acerca dos significados atribuídos em situações específicas, ou ainda, marcar significados chaves, importantes para a construção da explicação que estava sendo buscada, bem 
como rever o progresso da história científica.

As interações entre o professor e os estudantes geraram um discurso no plano da sala de aula, cujo conteúdo propiciou que os estudantes construíssem, para a situação em questão, explicações dirigidas pela teoria, pois, tais explicações, ocorreram sempre apoiadas por um modelo teórico que dava sustentação para as suas elaborações.

A análise microgenética se mostrou de especial importância para a compreensão das relações sociais que ocorreram nas interações entre os estudantes e o professor, pois, ao permitir um olhar que vai além da percepção do macro destas interações, possibilita que se apreenda detalhes da participação dos estudantes e do professor na construção do conhecimento que estava em negociação no plano social da sala de aula, o que pode contribuir para o planejamento das ações futuras relativas ao ensino e a aprendizagem de física.

Ao se planejar ações pedagógicas a partir de um olhar da Teoria Sócio-Histórica, atua-se no sentido de negociação de significados no plano social da sala de aula, uma vez que os conceitos escolares que estão sendo trabalhados não devem ser vistos como sendo antagônicos aos conceitos cotidianos ou não convencionais que os estudantes constroem na sua interação diária com os meios sociais com os quais se relacionam.

Se a ação pedagógica se dá no sentido de negociação de significados, torna-se, de especial relevância, que os estudantes sejam incentivados a se manifestarem a respeito do tema posto em discussão, de modo a que tenham participação na construção de seu conhecimento.

Neste sentido, na construção do conhecimento, a ênfase não se direciona nem para o estudante, visto como um ser ativo e capaz de construir sozinho ou com alguma orientação o seu conhecimento, nem para o professor, que detém o conhecimento a ser transmitido para o aluno, que é visto como um ser passivo e pronto para receber este conhecimento, mas, para a interação entre os próprios estudantes e destes, no caso do plano social da sala de aula, com o professor, uma vez que, de acordo com a lei genética geral do desenvolvimento cultural proposta por Vygotsky (2000b), a construção de conceitos, primeiro ocorre em um plano social, como uma categoria interpsicológica, para a partir daí ocorrer no plano psicológico, como uma categoria intrapsicológica.

\section{REFERÊNCIAS}

GOÉS, M. C. RA abordagem microgenética na matriz histórico-cultural: uma perspectiva para o estudo da constituição da subjetividade.In: Cadernos CEDES, XX, 50, 2000.

GOÉS, M.C.R. As relações intersubjetivas na construção de conhecimento. In GOÉS, M. C. R. e SMOLKA, A. L. B. (Orgs.). A significação nos espaços educacionais: interação social e subjetividade. Campinas: Papirus, 1997.

MEIRA, L. As bases semióticas e temporais da ZDP na sala de aula. In ANAIS DO II ENCONTRO IINTERNACIONAL DE LINGUAGEM, CULTURA E COGNIÇÃO: reflexões para o ensino. Belo Horizonte, julho de 2003.

MOISÉS, L. Aplicações de Vygotsky à Educação Matemática. Campinas: Papirus, 1997.

MORTIMER, E. F. Metic análisis and the dinamic of explanations im science classroom. In: III Conferência de Pesquisa Sócio-cultural. www.fae.unicamp.br/br2000. Tradução: Livre deAndrela Garibaldi.

MORTIMER, E. F. e SCOTT, P. Atividade discursiva nas salas de aula de ciências: uma ferramenta sociocultural para analisar e planejar o ensino. In: Investigações no Ensino de Ciências 3. Universidade Federal do Rio Grande do Sul; Porto Alegre, 2002 (site: http://www.if.ufrgs.br/public/ensino/revista)

OLIVEIRA, M. K. de. Vygotsky: aprendizado e desenvolvimento, um processo sócio-histórico. São Paulo: Scipione, 1993. 
OLIVEIRA, M. K. de. Vygotsky: aprendizado e desenvolvimento, um processo sócio-histórico. São Paulo: Scipione, 1993.

PALANGANA, I. C. Desenvolvimento $e$ aprendizado em Piaget e Vygotsky: a relevância do social. São Paulo: Summus, 2001.

PUREZA, O. Q. Um enfoque sócio-histórico do processo de ensino e de aprendizagem do conceito de energia mecânica. Dissertação (De Mestrado em Educação em Ciências e Matemáticas) - Núcleo Pedagógico de Apoio ao Desenvolvimento Científico, Universidade Federal do Pará, Pará, 2004.

TUDGE, J. Vygotsky, a zona de desenvolvimento proximal e a colaboração entre pares: implicações para a prática em sala de aula. In MOOL, L. C. Vygotsky e a Educação: implicações pedagógicas da psicologia sóciohistórica. Porto Alegre: Artes Médicas, 2002.

VYGOTSKY, L. S. Pensamento e Linguagem. São Paulo: Martins Fontes, 2000a.

VYGOTSKY, L. S. A Formação Social da Mente. São Paulo: Martins Fontes, 2003.

VYGOTSKY, L. S. Manuscrito de 1929. In: Educação \& Sociedade, ano XXI, n. 71, Julho de 2000b.

WERTSCH, J. V. Vygotsky y la formacion social de la mente. Barcelona: Ediciones Paidos, 1988.

WERTSCH, J. V. A voz da racionalidade em uma abordagem sociocultural da mente. In MOLL, L. C. Vygotsky e a educação: implicações pedagógicas da psicologia sóciohistórica. Porto Alegre: Artes Médicas, 2002. 